\title{
$\beta 146$ Vol $13-14$ \\ CYANIDE LEUCOENCEPHALOPATHY IN RATS AND OBSERVATIONS ON THE VASCULAR AND FERMENT HYPOTHESES OF DEMYELINATING DISEASES
}

\author{
BY
}

\author{
C. E. LUMSDEN
}

\author{
From the Department of Pathology, University of Aberdeen
}

Peculiar brain lesions have been produced in monkeys (Hurst, 1940, 1942), in cats (Ferraro, 1933), and in dogs (Jedlowski, 1937, 1938 ; Dechaume and Chambon, 1947) by the repeated subcutaneous injection of cyanides. Some have considered these lesions to show features similar to the spontaneous demyelinating diseases occurring in man and possibly in certain other mammalia, such as the monkey, sheep, dog, horse, moose, and fox.

The present report describes similar lesions produced by this means experimentally in the rat, and contrasts them with the lesions which resulted from experimental chronic carbon monoxide poisoning, and from experimental capillary embolism and disseminated capillary thrombosis which were successfully produced, perhaps for the first time, in this species.

These cyanide lesions in the rat develop only in the central white matter of the cerebrum and show a certain selectively demyelinating character unlike any of the other lesions achieved in this animal in these experiments. They have a remarkable histological similarity to the rare Marchiafava-Bignami disease of man, and indeed some similarity to Schilder's disease.

This experimental cyanide lesion in the rat brain is the only spontaneous or experimental lesion in this animal which is at all reminiscent of demyelinating disease. Furthermore, the rat appears to be quite insusceptible to the " experimental 'allergic' encephalomyelitis". which we have studied in the guinea-pig, and it is apparently completely resistant to hypersensitization lesions like the cerebral Arthus phenomenon (Lumsden, 1949).

The production, therefore, of this entirely artificial demyelinating disease in the rat, bearing as it does such a close similarity to that produced in the same way in the other species mentioned, suggests the existence of some fundamental biological mechanism in the brains of mammalia. Though it is much too premature as yet to say what this mechanism is, the obvious inference is that it may be an enzymatic mechanism peculiar to the oligodendrocyte-myelin sheath complex.

\section{The Production of Cyanide Lesions in the Rat}

One hundred and fifty rats were treated for one to forty days with daily subcutaneous injections, for the first five days of each week, of a sterile solution of potassium cyanide $(\mathrm{KCN})$. The average daily dose per animal was 2 to $6 \mathrm{mg}$. of $\mathrm{KCN}$, depending on the size and age. This is not a drug for which these animals acquire any real tolerance but, starting with half- to three-quarter-grown animals it is possible to increase the dose as they grow. Further, the doses given are just sublethal : for example, if in a given day some thirty animals all survive a dose of $5 \mathrm{mg}$. each, the dosage is raised on the following day to $6 \mathrm{mg}$. each. If three then die, the dosage remains at $6 \mathrm{mg}$. each until the day comes when there are no longer any casualties with this dose, and it is again increased. In this way a few casualties occur every day, or at most every two or three days, and timing of the onset of the lesions is for this reason very accurate. These 150 rats dying from chronic $\mathrm{KCN}$ poisoning have been examined histologically in from three days up to six months after the onset of poisoning.

The doses given are therefore nearly maximal, and almost invariably produce unconsciousness lasting from ten to sixty minutes and usually associated with prolonged convulsions and deep cyanosis. When the animal recovers from the convulsions and coma, it remains somewhat lethargic for several hours. During the second and third weeks fairly severe diarrhœa is common and may last a week or longer in animals which survive. This diarrhœa may clear up for a few weeks and then reappear, and is presumably an index of general intoxication. Paralyses are uncommon, though some animals before death develop torticollis, spasticity of the hind-limbs, and sometimes blindness. Impairment of sense of smell, as judged from reactions to food, has not been detected. As a rule the general condition of the animals remains remarkably good, though there is always some loss of weight.

Resúlts.-Out of nearly a hundred animals which died of acute intoxication within the first fortnight, only one had a cerebral lesion; but out of a total 

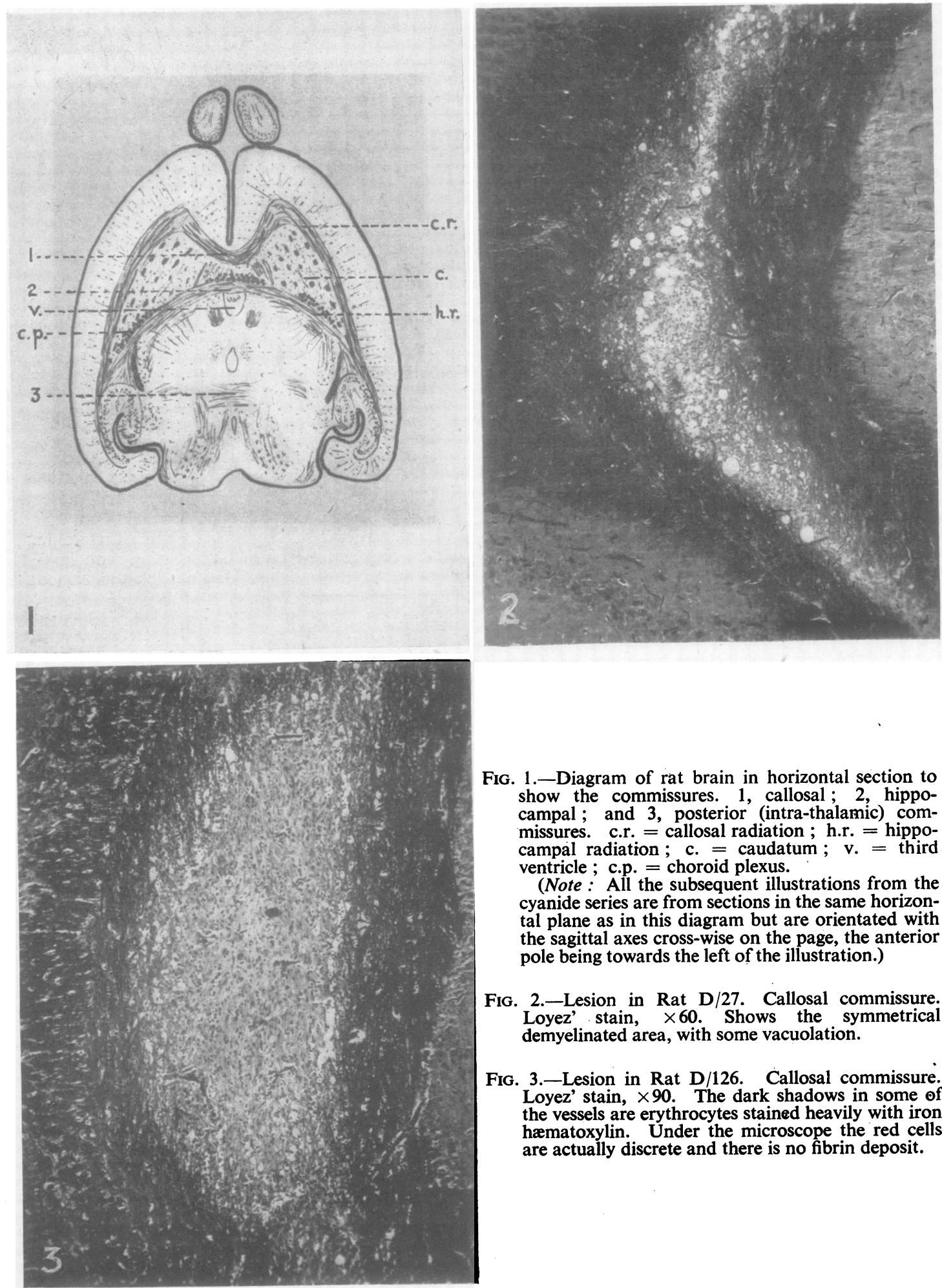

Fig. 1.-Diagram of rat brain in horizontal section to show the commissures. 1, callosal ; 2, hippocampal ; and 3, posterior (intra-thalamic) commissures. c.r. = callosal radiation ; h.r. = hippocampal radiation ; c. $=$ caudatum ; v. = third ventricle ; c.p. $=$ choroid plexus.

(Note: All the subsequent illustrations from the cyanide series are from sections in the same horizontal plane as in this diagram but are orientated with the sagittal axes cross-wise on the page, the anterior pole being towards the left of the illustration.)

Fig. 2.-Lesion in Rat $D / 27$. Callosal commissure. Loyez' stain, $\times 60$. Shows the symmetrical demyelinated area, with some vacuolation.

Fig. 3.-Lesion in Rat D/126. Callosal commissure. Loyez' stain, $\times 90$. The dark shadows in some of the vessels are erythrocytes stained heavily with iron hæmatoxylin. Under the microscope the red cells are actually discrete and there is no fibrin deposit. 

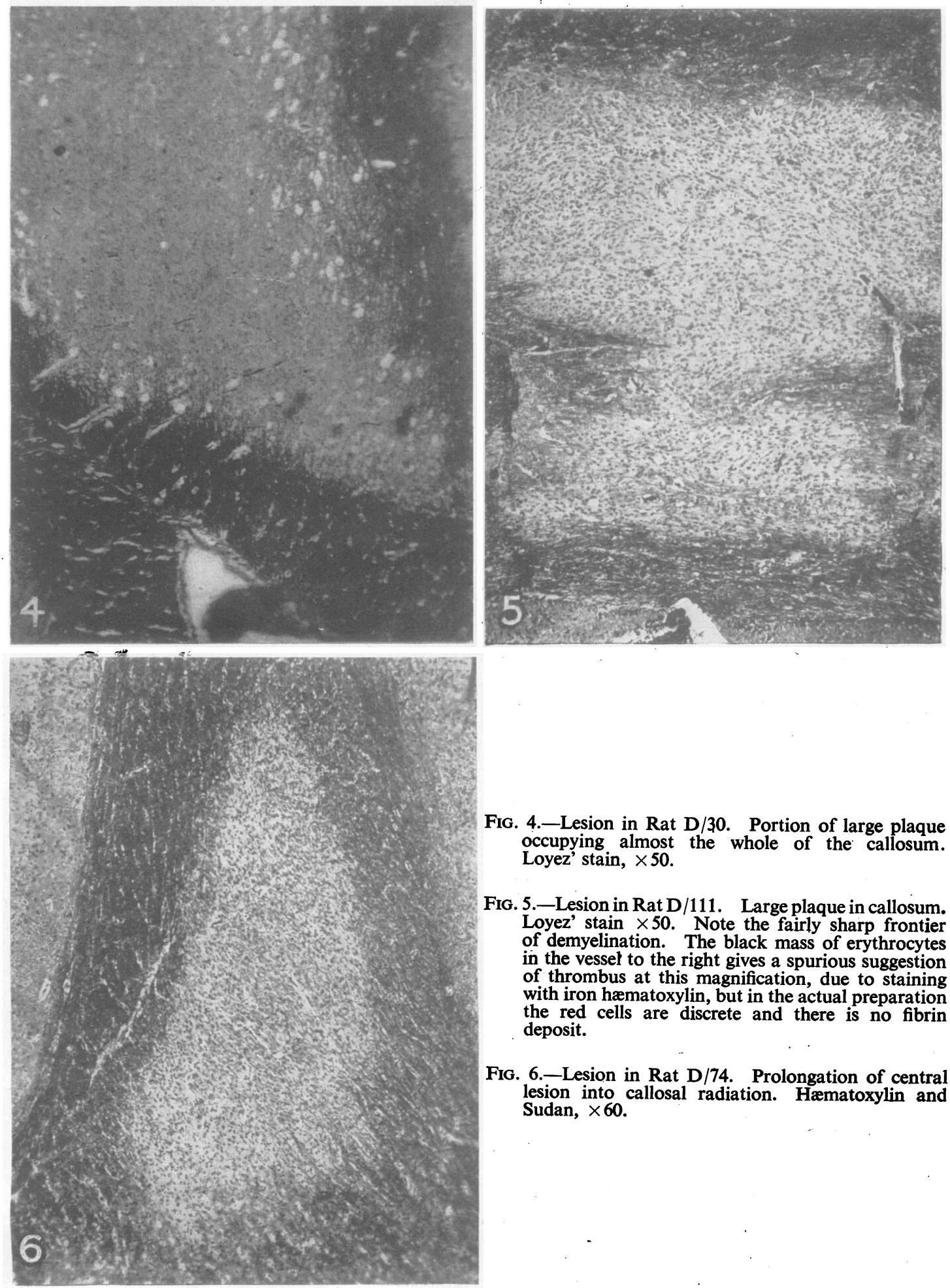

Fig. 4.-Lesion in Rat $\mathrm{D} / 30$. Portion of large plaque occupying almost the whole of the callosum. Loyez' stain, $\times 50$.

Fig. 5.-Lesion in Rat D/111. Large plaque in callosum. Loyez' stain $\times 50$. Note the fairly sharp frontier of demyelination. The black mass of erythrocytes in the vessel to the right gives a spurious suggestion of thrombus at this magnification, due to staining with iron hæmatoxylin, but in the actual preparation the red cells are discrete and there is no fibrin deposit.

Fig. 6.-Lesion in Rat $D / 74$. Prolongation of central lesion into callosal radiation. Hæmatoxylin and Sudan, $\times 60$. 

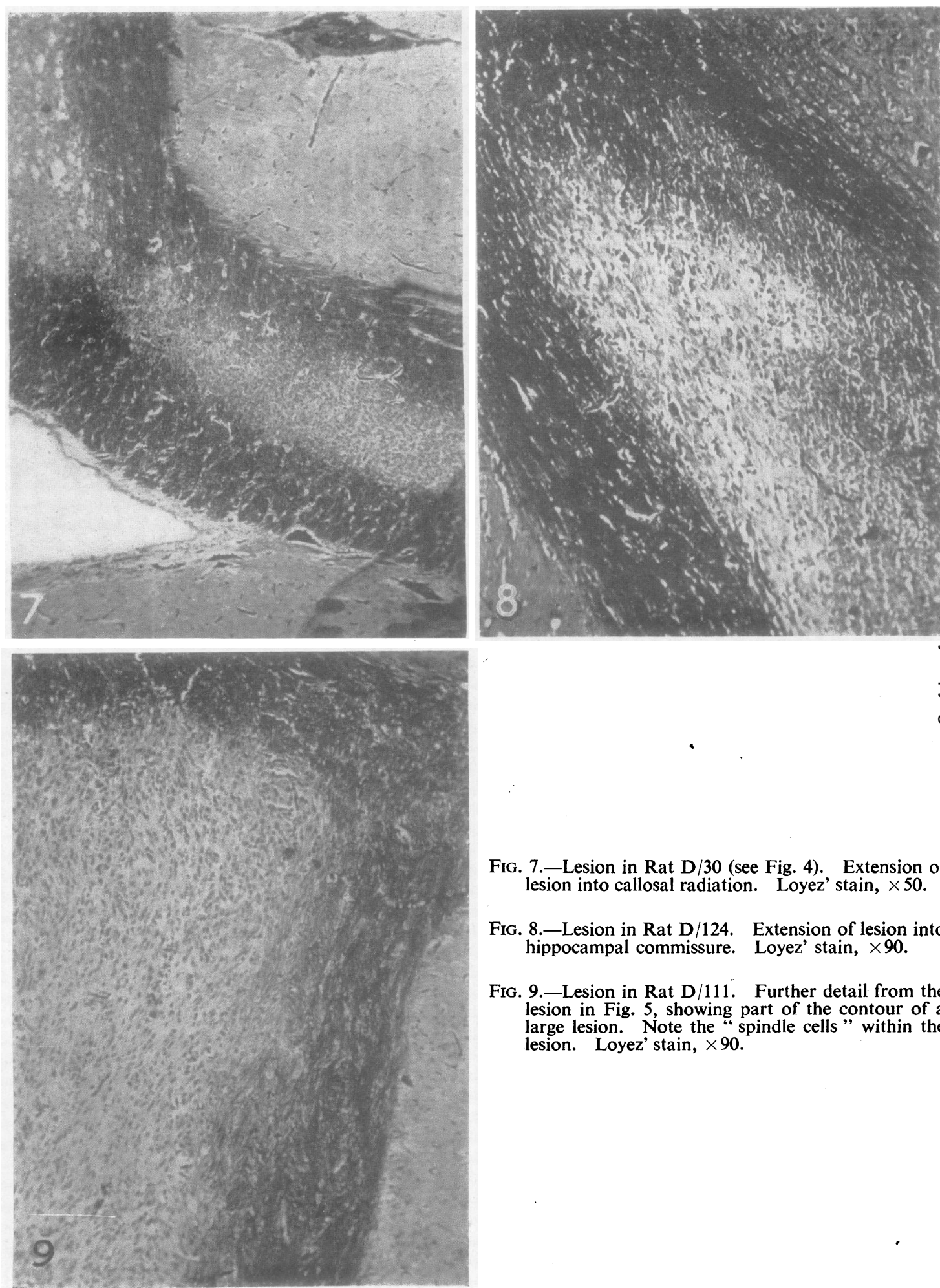

Fig. 7.-Lesion in Rat D/30 (see Fig. 4). Extension of lesion into callosal radiation. Loyez' stain, $\times 50$.

FIG. 8.-Lesion in Rat D/124. Extension of lesion into hippocampal commissure. Loyez' stain, $\times 90$.

Fig. 9.-Lesion in Rat $D / 111$. Further detail from the lesion in Fig. 5, showing part of the contour of a large lesion. Note the "spindle cells" within the lesion. Loyez' stain, $\times 90$. 

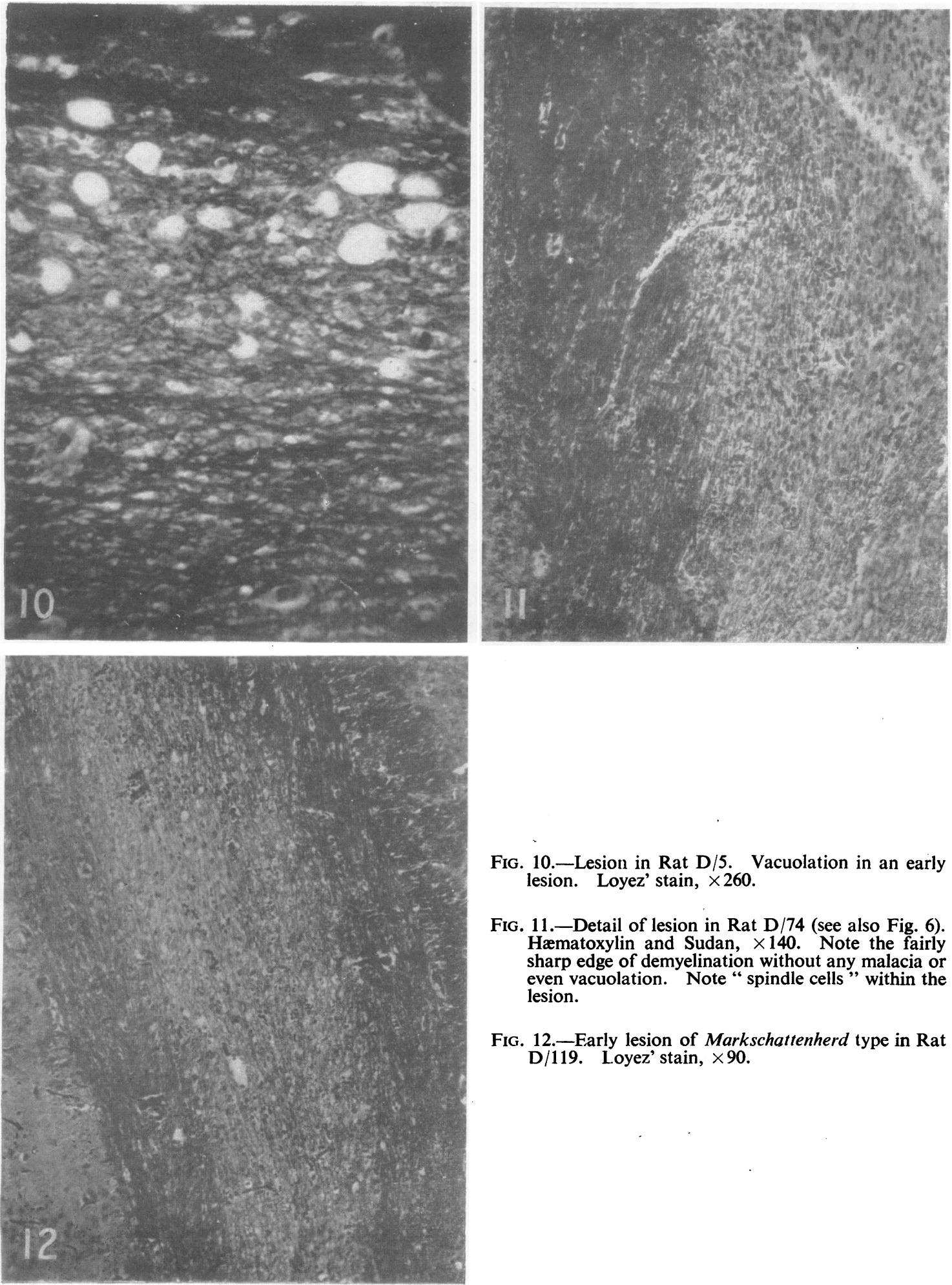

Fig. 10.- Lesion in Rat $D / 5$. Vacuolation in an early lesion. Loyez' stain, $\times 260$.

Fig. 11.-Detail of lesion in Rat D/74 (see also Fig. 6). Hæmatoxylin and Sudan, $\times 140$. Note the fairly sharp edge of demyelination without any malacia or even vacuolation. Note " spindle cells" within the lesion.

Fig. 12.-Farly lesion of Markschattenherd type in Rat D/119. Loyez' stain, $\times 90$. 

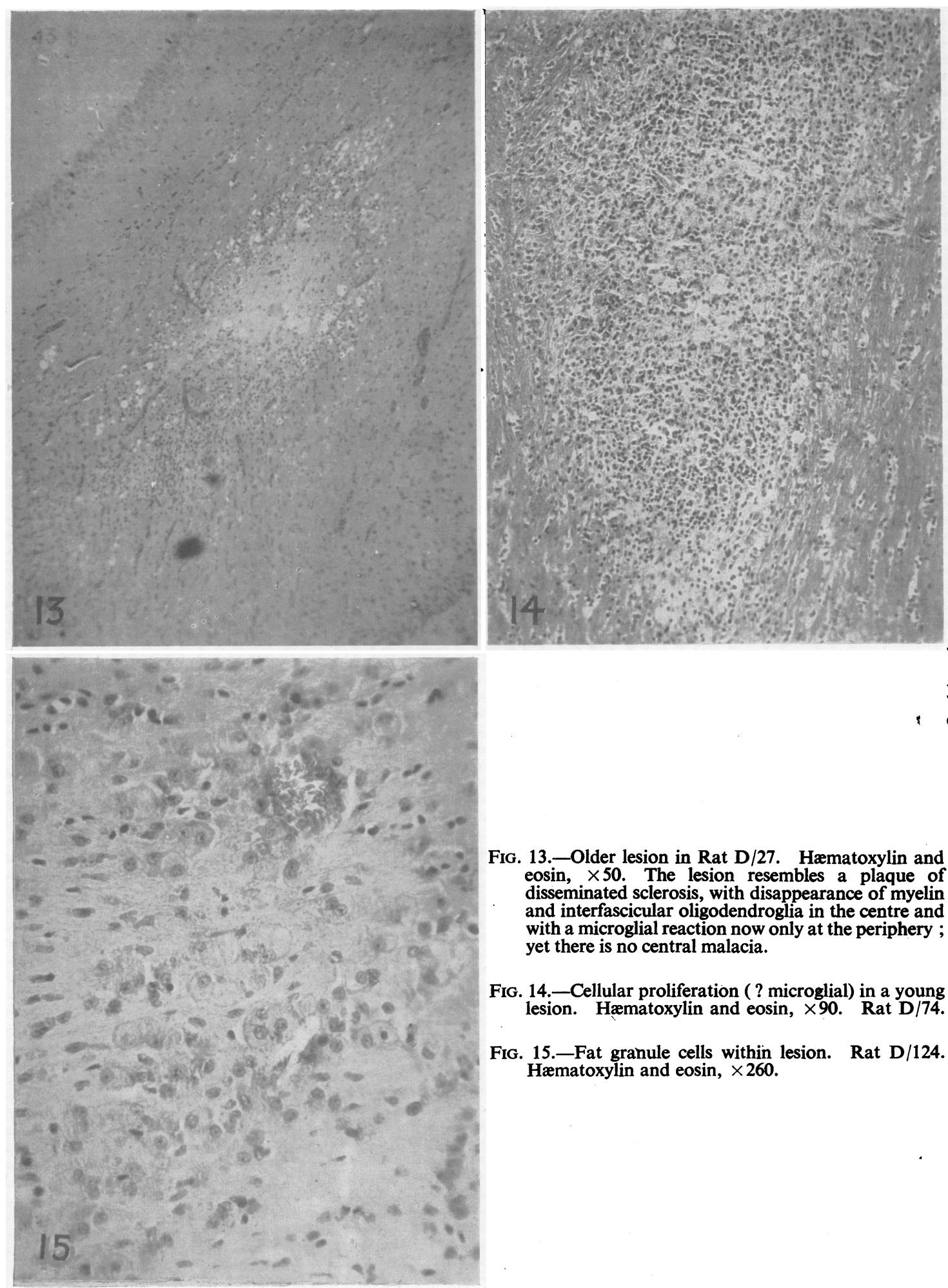

FIG. 13.-Older lesion in Rat $D / 27$. Hæmatoxylin and eosin, $\times 50$. The lesion resembles a plaque of disseminated sclerosis, with disappearance of myelin and interfascicular oligodendroglia in the centre and with a microglial reaction now only at the periphery ; yet there is no central malacia.

FIG. 14.-Cellular proliferation ( ? microglial) in a young lesion. Hæmatoxylin and eosin, $\times 90$. Rat $D / 74$.

FIG. 15.-Fat granule cells within lesion. Rat D/124. Hæmatoxylin and eosin, $\times 260$. 

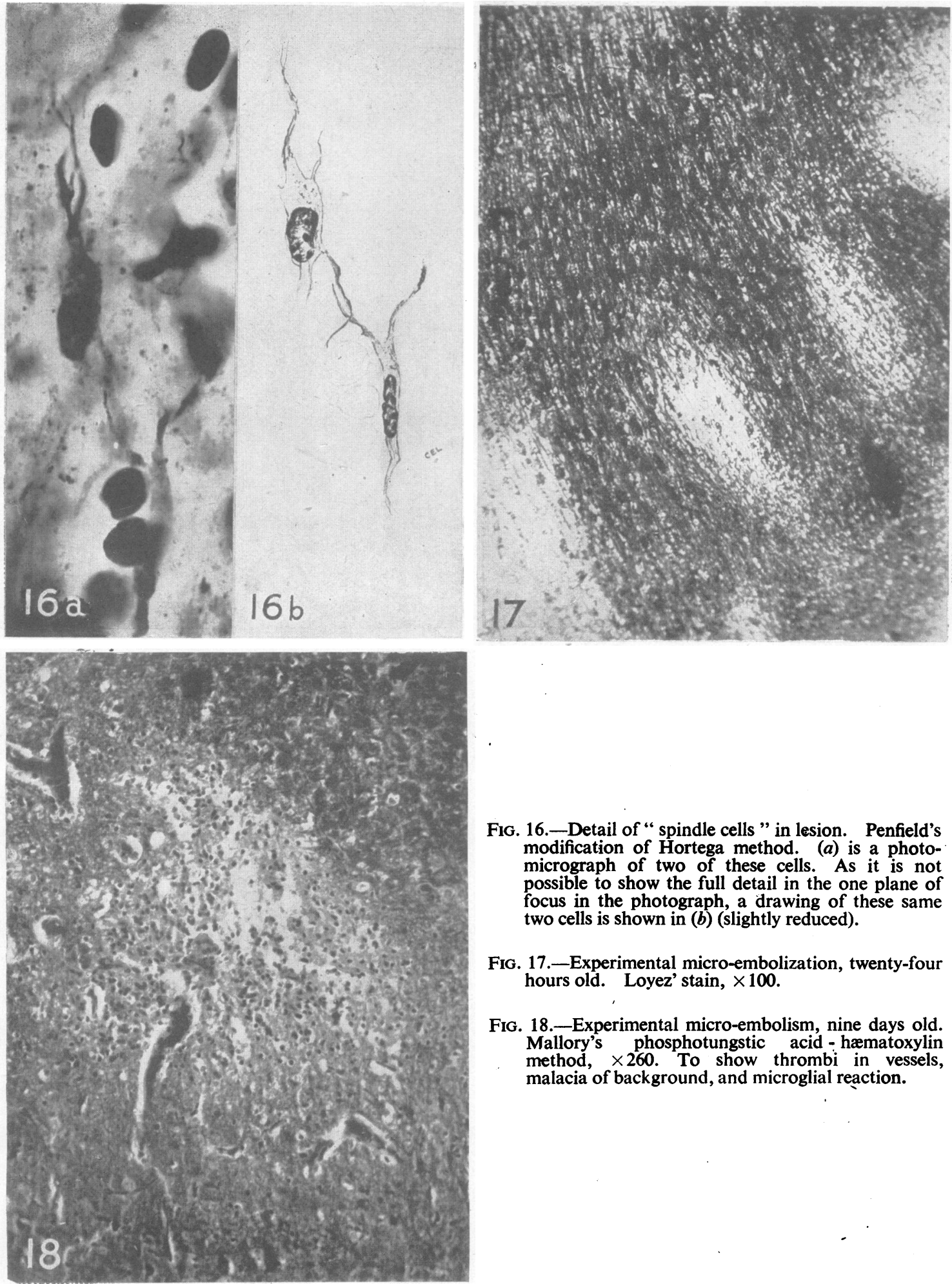

Fig. 16. - Detail of " spindle cells" in lesion. Penfield's modification of Hortega method. (a) is a photomicrograph of two of these cells. As it is not possible to show the full detail in the one plane of focus in the photograph, a drawing of these same two cells is shown in (b) (slightly reduced).

Fig. 17.-Experimental micro-embolization, twenty-four hours old. Loyez' stain, $\times 100$.

Fig. 18.-Experimental micro-embolism, nine days old. Mallory's phosphotungstic acid - hæmatoxylin method, $\times 260$. To show thrombi in vessels, malacia of background, and microglial reaction. 


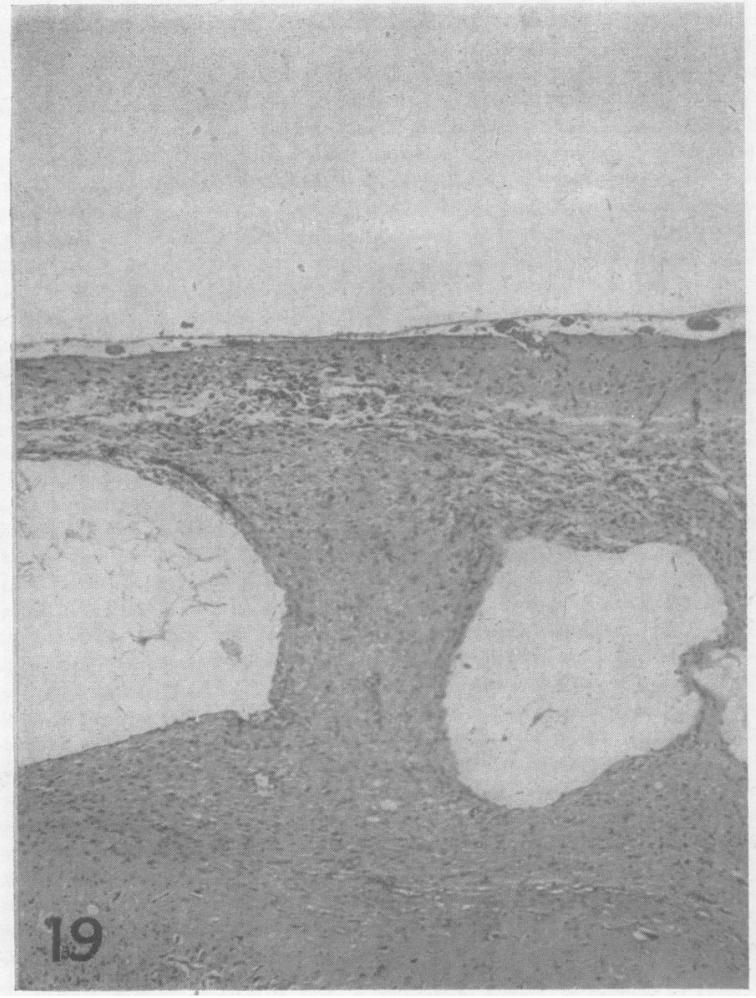

FIG. 19.-Experimental micro-embolism. Cysts in occipital cortex twenty days after embolization. Hæmatoxylin and eosin, $\times 50$.

of thirty-seven surviving an uninterrupted course of injections for periods of from two weeks to six months, no fewer than sixteen developed a remarkably uniform and characteristic lesion affecting symmetrically the central white matter of the cerebrum. Apart from some fatty change in the liver, histological lesions were limited to the brain. The heart was not enlarged, and there was no sign of infarction or of vascular thrombosis in any of the organs. Blood examinations were not carried out but none of the animals revealed any sign of anæmia at autopsy, nor did the spleens show any hæmosiderosis.

\section{Description of the Central Nervous System Lesions}

It is necessary first to refer to certain anatomical features of the rat brain. Because of the much smaller size of the animal the amount of white matter relative to grey is much less than in the sheep, the cat, or even the rabbit. The centrum ovale consists only of a thin strip of white matter on either side, and there is scarcely any corpus callosum. In the rat the corpus callosum is replaced by three well-marked commissures : an anterior

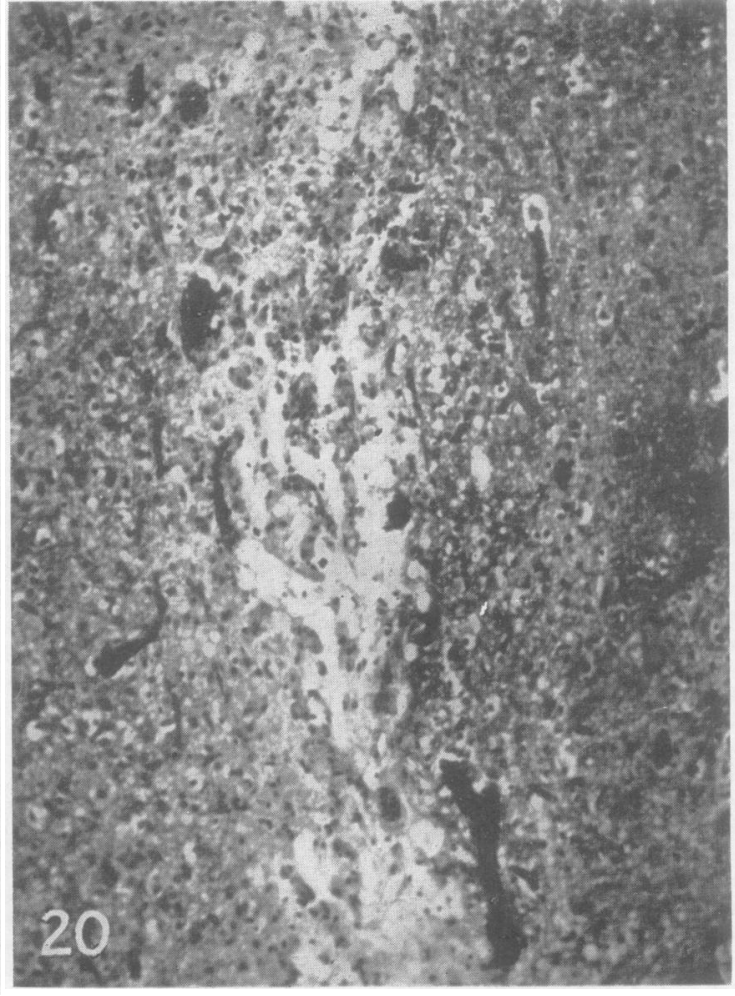

FIG. 20.-Experimental microthrombosis, nine days old. Mallory's P.T.A.H. method, $\times 260$. Thrombi, malacia, and microglial reaction as in Fig. 18.

or callosal, a central or hippocampal, and at a lower level a less robust posterior commissure. The grey matter of the cerebrum consists on either side of three well-defined groups : (1) the non-convoluted cerebral cortex with a rich laminar structure, (2) a large and well-defined mass of central grey matter the whole of which (Gurdjian, 1927 ) is referred to as the "caudate nucleus," and (3) the hippocampus, which forms a large crescentic roll of grey matter starting forwards and below and sweeping backwards and upwards, swelling out on either side into a ball-like mass (the cornu Ammonis) filling the space between the cortex on either side, and forming the bulk of the upper part of the brain. When the brain is cut horizontally in serial section on the freezing microtome, the first part of the white matter seen is a longitudinal strip in either hemisphere corresponding to the centrum ovale; $0.1 \mathrm{~mm}$. deeper the cornu Ammonis comes into view, and the white matter of the centrum ovale splits to encircle this structure, but in front of the cornua it merges with the white matter of the opposite side to form an equilateral figure with incurved sides, measuring about $1.5 \mathrm{~mm}$. across its centre. It is this structure which, in the more precise anatomical sense, is homologous with the corpus callosum in man. In the rat, however, this is a shallow structure rarely allowing more than twelve to 
fifteen 10-micron sections, when it is split transversely by the fornices into the callosal and hippocampal commissures (Fig. 1). At a lower level this latter splits again and a commissural band-the posterior commissureappears behind the caudal end of the third ventricle and the commissural organ (which is very well developed in the rat).

From this description it will be appreciated that the corpus callosum, and the callosal and hippocampal commissures, which together form almost the whole of the cerebral white matter in the rat, are all in very close continuity with each other, being simply the digitations or prolongations of the centrum album, and it is only because of the smallness of the brain that there is an appearance, even in histological preparations, of an abrupt transition from one part to the next. To describe, therefore, in this work, a lesion of the corpus callosum in one rat, a lesion in the callosal commissure in another, and a lesion of the hippocampal commissure in a third, is not to imply a multiplicity of sites of election by the pathological process; the result is determined by the particular level of the sections described or from which the photomicrograph has been taken; and it will be appreciated, therefore, that a variation of 50 microns appears to make an enormous difference.

As in other small mammals, the white matter of the rat brain has a very orderly fascicular arrangement and, in particular, the interfascicular oligodendroglia forms an almost continuous chain of nuclei between the nerve fibres. These nuclei are large and vesicular and contrast quite sharply in the rat with the microglial nuclei. Pathological alterations in these two types of cells are therefore readily recognized even in ordinary paraffin sections: a great advantage where the volume of tissue is so small. In some instances the brains were mounted whole in paraffin, and sections were stained by hæmatoxylin and eosin, Loyez' hæmatoxylin, and Mallory's phosphotungstic-acid hæmatoxylin methods. In other instances the brains were cut serially on the freezing microtome and preparations stained by Sudan III and hæmatoxylin, Spielmeyer's method for myelin, Bielschowsky's method for neurofibrils, and Penfield's modification for microglia and oligodendroglia.

The earliest, and smallest, lesions seen in the sixteen positive cases lie in the centre of the callosal commissure alone (Figs. 2 and 3). More extensive lesions not only involve the central portions of the callosal commissure but, spreading dorsally, occupy symmetrically almost the whole of the corpus callosum itself (Figs. 4 and 5). These more extensive lesions may remain localized to the callosum, but not infrequently (Figs. 6 and 7) extend out for a considerable distance either in the callosal commissure or radiation as it swings out over the caudate nucleus, or into the hippocampal commissure as in Fig. 8.

The lesion does not always start in the centre of the callosal commissure, however; the largest appear to have started in the corpus callosum itself and thence the lesion extends as a tongue-like process into the callosal radiation on either side without the lower levels of the anterior commissure being involved at all. Consequently, sections at a lower level will in such cases reveal two apparently discrete but symmetrical foci of demyelination in the callosal radiation, as exemplified by $R$ at $D / 74$ from which Fig. 6 was taken.

The histological features of the lesions are remarkably constant-despite the fact that the duration of the experiment might range from fifteen to ninety days. The lesions appear to develop suddenly, and they pursue a uniformly rapid course to death. Consequently there is no essential histological difference between the lesions in Rat $D / 111$ (Fig. 5), which died thirty days after the onset of the experiment, and Rat D/30 (Fig. 4), which died ninety-one days after; on these as well as on clinical grounds the lesions are evidently of similar age. Weston Hurst made this same observation in his experiments on monkeys ; he affirmed that $\mathrm{KCN}$ is " certainly not a cumulative poison," and that " in a remarkable manner, necrosis often developed suddenly and simultaneously over wide tracts of the white matter after a dose of the poison tolerated previously on many occasions."

The individual lesions, as can be seen from the photomicrographs, are always fairly sharply demarcated but they lack, perhaps, the abruptness of the contours of plaques of disseminated sclerosis in man. Fig. 9 is a slightly enlarged view of the same plaque as in Fig. 5. It shows, in a Loyez' preparation, the appearances of a typical lesion with this fairly sharp demarcation, but all round the periphery strands of myelin sheaths traverse the edges of the lesion. Furthermore in certain instances, there is distinct fenestration of the tissue round the periphery of the lesions, as can be seen in Figs. 2 and 4. In the earliest lesion of all, which appeared after nine days only of cyanide treatment, the lesion consisted simply of a thin band of partial demyelination associated with this fenestration of the tissue (Fig. 10). On the other hand, in instances such as in Figs. 6 and 9, no such fenestration is seen and the lesions, being more selectively demyelinating, are more sharply demarcated than the others.

The demyelination is undoubtedly selective here, for in all instances it is much more extensive than any destruction of axis cylinders that does occur. 
Fig. 11, from a hæmatoxylin and Sudan III preparation, shows quite clearly the transition from the normal myelinated tissue to the demyelinated area. The fascicular structure is still preserved throughout the lesion and there is no central malacia. Even in those cases with peripheral fenestration there is never any softening in the centre of the plaque such as occurred in the much smaller embolic and thrombotic lesions produced in the other experiments to be described later. Nor, by the same token, is there any tendency here to tissue shrinkage and distortion, nor to cyst formation such as occurs in experimental thrombotic and embolic lesions in this animal. In the absence of other than a minimal degree of axis cylinder destruction, the physical structure of the tissue remains unaltered; in this sense, the tissue in this demyelinated lesion is " isomorphic" with the parent tissue in the same way as it is, for instance, in disseminated sclerosis in man. Another feature, too, of the earlier lesions, and one indeed reminiscent of the primary demyelinating diseases, is the occasional appearance of Markschattenherde, as in Fig. 12.

Unfortunately, this is a lesion which, when it develops at all, evolves rapidly and is soon fatal ; even where there have been paralytic features to signal the presence of a lesion in formation and the animal has in consequence been spared further injections, such animals have died within a week. Consequently, the remote fate of such a lesion, once established, if it were not fatal, has not been determined. Fig. 13 suggests, however, that the lesion might well evolve as a plaque of disseminated sclerosis or of Schilder's disease, for its centre is remarkably void ; the patch is completely demyelinated, the oligodendroglia has completely disappeared (compare the fascicular white matter to the right) and even the microglial reaction has subsided in the centre though it is still active at the periphery. Yet the centre is not softened as it would be in a necrotic process. And in such lesions where Bielschowsky preparations have been available there has been ample evidence of at least partial persistence of axis cylinders.

Though quiescent lesions, such as that $n$ Fig. 13, are sometimes seen, the striking feature in most is the great increase in cellularity within the area. Fig. 14, from Rat D/74, shows the edge of such a lesion and reveals the character of these proliferated cells. Their nuclei are smaller and darker than those of the oligodendroglia in the surrounding parenchyma. Furthermore they (or at any rate some of them) evolve into obvious fat granule cells, as can be seen in Fig. 15 from Rat D/124. Usually, these fat granule cells are located round the periphery of a lesion and are, rather surprisingly, less abundant than one might reasonably have expected from the extent of the lesion. In fact in some instances no sudanophil fat was present at all.

In the centres and not infrequently up to the edges of the lesions there are spindle-shaped cells of obscure nature. Attempts were made to trace transitional forms between them and the oligodendrocytes in the immediate vicinity. But the nuclei of these spindle cells are more compact, often distorted, and stain a good deal more darkly than oligodendroglial nuclei (Fig. 16). Their cytoplasm also impregnates fairly readily, like rat microglia but unlike rat oligodendroglia by Penfield's method. Since certain cells amongst them are undoubtedly fat granule cells it seems legitimate to conclude that the cell type is microglial; it is possible, however, that some of them at least are degenerate astrocytes. But it has to be admitted that these spindle cells are peculiar in my experience with rat and guinea-pig brains. They recall similar cells which King and Meehan (1936) described in Marchiafava's disease, and also the peculiar spindle cells which Greenfield and King (1936) described in disseminated sclerosis and which they thought were probably not microglial.

In the grey matter, apart from minor cytoplasmicin changes-and in notably variable quantity from case to case-there is no sign of gross damage to the neurones. Such alterations as are seen from time to time in the perikarya seem to depend more on the time and mode of death than on any other factor, and are presumably a measure of the in tensity of the acute terminal cyanide intoxication.

The paucity of astroglial reaction in Mallory phosphotungstic-acid hæmatoxylin preparations is one of the striking features of the lesions ; although, as has been seen, it is just possible that some of the peculiar spindle cells are degenerating astrocytes. Nor, apart from the microglial element, is there any mesodermal reaction; for the perivascular spaces and pia-arachnoid meshes are notably devoid of granulocytes, lymphocytes, and fibroblasts.

Neither in the lesions nor in the rest of the brain is there any trace of thrombosis. For comparison, we have the subsequent series of experimental embolism (with propagated thrombus) and experimental thrombosis, so that adequate control material has been plentiful. At most there is occasionally in the fixed and stained preparations of the cyanide brains a little homogeneous hyaline coagulum, presumably plasma ; but this is found no more readily in the brains with cyanide lesions than in normal brains treated by the same histological techniques. Certainly there were no vessels "which are stuffed with fibrin, dilated and beaded with curved strands of fibrin or masses of fibrin and 
masses of platelets" which, even for Putnam, the leading exponent of the thrombotic origin of the demyelinating diseases, are apparently the minimal criteria of thrombosis (1938). Furthermore, there was no sign of any hæmorrhage nor focal hæmosiderosis such as were commonly found in the experimental embolic and thrombotic lesions of the subsequent experiments. On the contrary, even the venules within the lesions of the cyanide series appear unaltered and contain discrete erythrocytes such as can be seen towards the top of Fig. 15.

\section{Note on Experimental Cerebral Capillary Embolism in Rats}

Method.-For the production of multiple capillary emboli in the brains of rats, intracarotid injections of liquid paraffin were at first attempted. Technically, however, this proved almost impossible because the paraffin was too viscous for the very fine needles which had to be used ; and, in any case, even when a drop was successfully delivered it caused a fairly massive infarction. Accordingly, use was made of ordinary pharmaceutical cod-liver oil previously tested for sterility. This was sufficiently fluid to be injected fairly easily, and by a very simple technique it was found possible to introduce it in very small droplets. This technique is to support the exposed carotid artery, elevated out of the wound, on the opened prongs of a small curved Spencer Wells forceps so supported on a pad of cotton wool that the distal prong compresses the wall of the vessel slightly, thus causing the portion behind to become greatly engorged. In this way it is easy to pass the fine 27-gauge needle right into the lumen. Using a fine tuberculin syringe, very gently, screw-wise pressure is applied so that a minute globule of the emulsion exudes from the end of the needle. This, being of opaque white colour, is readily seen through the thin translucent wall of the vessel. Then, without any further delivery of the minute bead of emulsion from the syringe, the distal prong of the forceps is depressed slightly to relieve the engorgement of the lumen of the vessel. The sudden surge of blood through the artery whips away the partially formed droplet, which is seen to break up into even finer particles as it is swept away. It is surprising how, after practice, not only the amount of emulsion injected but even the size of the embolic droplets can be controlled. By injecting such minute globules with the instruments in situ over a period of ten to fifteen minutes, numerous lesions can be produced though the total dose may not exceed $0 \cdot 1 \mathrm{ml}$.

The lesions produced are almost always in the homolateral hemisphere only, though occasionally a few small oil emboli are found in the opposite side and usually in the field of distribution of the anterior cerebral artery.

Following the injection, the carotid artery has to be ligated above and below, or otherwise there is always a brisk hæmorrhage from the needle hole in its wall. It is not so much that this hæmorrhage is likely to prove fatal -it is surprising how much hæmorrhage the rat can stand -but that it introduces an uncontrollable variable. It has been found by using a series of control animals that simple unilateral ligation of the carotid in the rat does not in itself produce lesions, there being an obviously adequate collateral circulation through the circle of Willis in this animal. And it may well be that the reduction of blood flow which results from ligation helps the experiment by minimizing the chances of dislodgment of the oil emboli once they are in situ.

By this technique 150 rats have been embolized. Some do, of course, develop gross infarctions which may kill either within an hour or two or after about a week's interval, during which the animals manifest complete hemiplegia and often necrosis of the globe of the eye. On the other hand others (about 40 per cent.) escape detectable lesions altogether. But out of the 150 there were twenty-one " positive" cases showing multiple capillary blockages only. These milder cases may die at any time in the first few weeks, though most had the disease confirmed histologically when representative groups were sacrificed on the twentieth and fortieth days respectively.

Since the purpose of the present paper is merely to give information about these lesions for comparison with the cyanide lesions, we need not enter into detailed description of the histological findings. The accompanying photomicrographs show representative lesions of different ages to illustrate the evolution of the process. One-day and nine-day lesions are illustrated in Figs. 17 and 18 respectively. These lesions are manifestly necrotic. Microglial reaction is quick and often intense ; and fat granule cells appear in a few days (as early as four or five) and are always abundant. Normally by twenty days the small infarcts have undergone shrinkage and the microglial reaction is beginning to subside, to be replaced by a reactive gliosis accompanied by mesodermal scar formation. Numerous macrophages laden with iron pigment are usually a marked feature by this time. Some larger lesions may even show liquefaction and cyst formation (Fig. 19). By forty days the smallest lesion has become reduced to a minute glial and mesodermal scar, easily overlooked and ill-demarcated and not at all like any plaque of disseminated sclerosis " découpée comme à l'emporte-pièce."

These lesions, at these various stages, are widely scattered throughout the hemisphere, the cornu Ammonis and the deeper laminæ of the cerebral cortex being the most frequent sites. In no single instance has any lesion at all resembling the cyanide lesion resulted.

\section{Note on Experimental Cerebral Thrombosis in Rats}

By the injection of quinine and urethane solution in like manner into the carotid artery of rats, it was 
found possible in a small proportion of animals to produce minute scattered softenings.

Fig. 20 shows such a lesion, eight days old. It shows a thin linear softening in the mesencephalon, with fenestration of the tissue and a frank fatgranule cell reaction. There is complete necrosis of fibres and sheaths in the affected area, and the lesion is very similar to the embolic softening which was seen in Fig. 18, a lesion of about the same age and extent. By this technique, despite the use of over a hundred animals, it has not been possible so far to produce more than five positive cases of the type wanted with multiple small discrete lesions older than ten days. In all these five, however, the softenings are strictly comparable with those in the series with experimental oil embolism. But there was one striking difference. Whereas in the embolic cases the lesions were in the cerebral cortex, the cornu Ammonis, and hippocampus, the thrombotic lesions were without exception mesencephalic. The reason for this is still under investigation but it probably depends upon the different capillary angio-architecture in the mid-brain and the cerebrum.

In these thrombotic lesions the persistent thrombi are easily found in the small central or marginal vessels (Fig. 20). The lesions are typical small infarcts with ragged edges and showing complete necrosis of all the tissue elements. Nothing in the nature of the lesions in the cyanide cases has occurred in this experimental thrombosis series, any more than in the experimental embolism series.

\section{Note on Experimental Carbon Monoxide Poisoning in Rats}

Thirty-one rats were exposed daily in a coal-gas chamber for thirty to sixty seconds in a high concentration of $\mathrm{CO}$ producing complete unconsciousness lasting for ten minutes or longer, usually with epileptiform convulsions, and succeeded by a prolonged period of carboxy-hæmoglobinæmia. This was carried out for three-week periods, with seven to ten day intervals between each period, for as long as three months in many of the animals. Only in three rats were lesions produced. These were all of the nature of multiple tiny foci of microglial reaction in relation to degenerating perikarya, and they occurred in the cerebral cortex, caudate nucleus, cerebellum, and occasionally the cord.

Nothing was seen at all resembling the diffuse lesion of the central white matter which sometimes occurs in man (Eros and Priestman, 1942) and which can be reproduced in monkeys. It was in fact chiefly to see whether this diffuse CO lesion could be produced in rats and, if so, whether it resembled the cyanide lesion, that the present experiment was carried out.

\section{Discussion}

It has been seen that in sixteen cases with positive cyanide lesions there was a remarkable uniformityindeed identity -in the lesions from case to case. Invariably the lesions were symmetrical and occupied the central white matter of the cerebrum, being limited entirely to this region and not involving the mid-brain, cerebellum, or cord. They did not involve the grey matter, though the parent neurones of the damaged commissural fibres might show secondary degenerative features. Certainly there were no multiple focal lesions such as the asphyxial lesions of carbon monoxide poisoning in these animals and the frankly thrombotic and embolic lesions experimentally produced. Furthermore, it is notable that the sites of election of all these other experimental lesions in the rat were elsewhere than in the central white matter.

Histological examination failed to reveal any evidence of thrombosis in the brains of the cyanide intoxicated series and the blood vessel walls showed no visible evidence of damage. Nor was there any appreciable œdema : where there was some fenestration of the tissue at the margins of the lesions, frozen sections stained with Sudan usually revealed this to be due to fat.

It may be argued that the small number of threee 7 cases with histological lesions which were produced 응 in the $\mathrm{CO}$ intoxication series are scarcely adequate for comparison with the cyanide lesions. But, in fact, it is fairer to take into account that, of the thirty-one animals exposed to the severe, prolonged, of and repeated $\mathrm{CO}$ asphyxia, none developed lesions resembling the cyanide lesions, whereas, of 150 animals exposed to chronic cyanide poisoning, none developed the focal asphyxial lesions of $\mathrm{CO}$ poisoning. It would seem, therefore, that in the production of the cyanide lesion some mechanism is at work other than asphyxia operating directly upon the neurone. And, vice versa, if in chronic CO poisoning there is a "toxin" operating directly upon the neurone, it acts mainly upon the nerve cell nucleus and not upon the axis cylinder or its sheath or sheath cells.

As to whether the mechanism of production of the cyanide lesion may be an indirect one acting through the medium of vascular occlusion, we have shown that it is at least not one of thrombosis. We cannot, of course, rule out on histological examination the possibility of a regional vascular occlusion caused by vasospasm; but this suggestion seems to me an improbable explanation for the cyanide lesion. Villaret and Cachera (1939) have demonstrated convincingly by direct observation how such spasm of the small vessels (at least the cortical ones) 
can occur, but it was precisely by microembolization that they were able to induce this spasm. It is probable, too, that asphyxia alone (Penfield, 1933) will cause spasm of these small cerebral vessels. Furthermore, one of the most potent spasmodic agencies is the intracarotid injection of quinine and urethane, for we have frequently seen powerful spasm in the carotid artery itself on injection of the quinine and urethane solution used in the experimental thrombosis series. It seems legitimate to expect, therefore, that by microembolization, intraarterial coagulants, or even by $\mathrm{CO}$ asphyxia alone, we might be able to reproduce at least one lesion of the "cyanide" type were spasm to be the mechanism which initiates the cyanide lesion.

To digress for a moment, it is fully appreciated that, apart from producing ischæmic necrosis in the territory of supply, blockage of the small vessels leads to considerable increase in the permeability of the walls of the vessels proximal to the obstruction. This has been very neatly demonstrated by Broman in a recent series of communications. He has employed the technique of following up the experimental embolization with the injection of a solution of trypan blue which, in such cases, he has found may penetrate the vessel walls for some considerable distance proximal to the obstruction. This increased permeability, he maintains, is due to atonic dilatation. By direct observation he has shown that as a result of the temporary capillary occlusion and consequent impairment of nutrition of the capillary wall there may follow a period of several hours during which increased mural permeability persists. Temporary arrest of the capillary circulation from spasm, or atony, or toxic damage to capillary walls, or from occlusion caused by particles of conglutinated blood cells, can therefore well explain, for instance, the " multiple acute softenings" in man which may follow a multitude of toxic and asphyxial conditions like CO poisoning, arsenical encephalopathy, uræmia, serum encephalitis, and bacterial intoxications like dysentery (an example upon which Spielmeyer himself was wont to dwell), without its beingnecessary to have recourse to Putnam's hypothetical evanescent thrombi. In the same way this œdema, the mechanism of whose production Broman's work does much to elucidate, can damage the surrounding parenchyma and in some instances act in a remarkably selective way upon the more vulnerable myelin sheaths and oligodendrocytes (Greenfield, 1938). It is not Putnam's problem of evanescent thrombi, but this very real probability that vascular stasis will in itself produce necrotic lesions, partial (demyelinating) as well as complete, of the parenchyma without primary thrombosis which is the very kernel of the "vascular problem" in the spontaneous demyelinating diseases.

There is not space here to discuss at length either the relationship of the " multiple acute softenings" (Hassin's term) occurring in toxic conditions, or the lesions of multiple cerebral phlebothrombosis, with the "true demyelinating diseases of man. Undoubtedly there occur occasional lesions of vascular origin-infective, toxic, thrombotic, or embolic in nature-which mimic disseminated sclerosis by reason of the subtotal necrosis of the parenchyma round the vessels, the more vulnerable myelin sheaths and associated oligodendroglia showing a slightly greater degree of damage than the more resistant perikarya and axones. For the most part, however, this apparent demyelination is spurious, due to the fact that a myelin stain will not distinguish between truly selective demyelination and necrosis of the whole axone. Up to a point, certain physical agencies like pressure due to tumours or to traumatic œdema (Greenfield, 1938) will act differentially by operating in that narrow margin between the thresholds of physical vulnerability of the sheath and of the axone. But in such conditions the apparent integrity of the axone is short-lived, and it is not possible for the demyelination to progress and extend as it does in a plaque of disseminated sclerosis while the axis cylinder remains structurally and, to a considerable extent, probably functionally intact.

Returning now to the interpretation of the experimental cyanide lesion in the rat, it has, then, peculiarities which distinguish it from vascular, asphyxial, and other toxic conditions in this animal and from the similar lesions which occur in the human brain. Perhaps its closest analogue in human pathology is the Marchiafava-Bignami disease, the curious degeneration of the corpus callosum caused by alimentary intoxication from excessive and persistent use of Italian claret wine.

Whether this gives us a link with Schilder's disease remains to be examined. Recently there has been a greater tendency than ever to assume that the classical form of Schilder's disease and the familial leucodystrophies of the Krabbe, Scholz and Ferraro types are all the same disease process and that, by inference, Schilder's disease is an inborn error of myelin metabolism. For this reason the old insistence on the distinction of " exogenous" and " endogenous" forms (Bielschowsky and Henneberg, 1928) has regrettably been dropped. This is a problem with which it is intended to deal in a separate study. But for the moment it is worth while calling attention to a case of Schilder's disease, reported by Jervis and Kind- 
wall (1942), apparently caused by chronic ergotamine poisoning; and to Verhaart's report (1941) on chronic lead poisoning as a cause of diffuse sclerosis in infants. So it may be that we shall have to return to the search for possible exogenous toxins in Schilder's disease. In this respect Dechaume and Chambon (1947) have recently drawn attention to the possibility of intoxication with cyanides themselves, occurring in man as a result of the consumption of bread made from flour reinforced with meal from the bean Phaseolus lunatus, which contains a large percentage of cyanogenic glucosides.

Since all the evidence assembled here is contrary to a simple vascular or simple asphyxial hypothesis, how are we to seek to explain the experimental cyanide lesion? In cyanides, we are undoubtedly dealing with toxins which have a special affinity for the central white matter of the brain. Cyanides are potent enzyme poisons, and it has; of course, been suggested by several authors that the occurrence of this curious lesion in the white matter of the mammalian brain is evidence of the existence of an enzyme mechanism there, presumably resident in the myelin sheath. The extreme susceptibility of the oligodendroglia to autolytic enzymes suggests, further, that the cyanide may operate on the myelin sheath by damaging this cell, and that in fact it is the oligodendrocyte which is the metabolic centre of the myelin unit. But in employing this hypothesis we have to remember that such an enzyme system is not the only one, either in the brain or elsewhere in the body, to which cyanides are poisons. It is the special susceptibility of this hypothetical enzyme system which presents the real problem, and the fact that the lesion produced by poisoning of this system should be a single symmetrical focus limited to the central white matter of the cerebrum and not affecting the brain stem, cerebellum, or cord. During the phase of acute intoxication with the cyanides it is to be presumed, surely, that several different cellular enzyme systems throughout the various organs of the body are functionally disturbed ; but, short of somatic death, this disturbance is completely reversible. It would be the special and peculiar quality, therefore, of the myelin enzyme system in certain susceptible regions of the brain to be irreversibly damaged.

But if this were the whole story we would expect a series of lesions of different ages each dating to one or other specific episode of acute intoxication. As it is we have the curious feature, to which Weston Hurst first drew attention, that when this lesion develops it does so suddenly, and progresses uniformly to death. It may be, therefore, that the demyelination is a secondary phenomenon, sui generis; that the toxic or lytic agent which ultimately does the damage to the white substance is not the cyanide itself but one derived and spreading from a central focus within the white matter.

If such were the case we should have indeed in this cyanide lesion a direct demonstration of the truth of Marburg's original hypothesis (1906) that the demyelinating diseases are primarily caused by the liberation, within the brain substance itself, of a myelinolytic ferment. And we should have an explanation as to why the search for myelinolytic ferments in the blood and in the cerebrospinal fluid have been so singularly disappointing. If we are to continue our search for myelinolytic ferments in demyelinating disease we must therefore re-orientate our approach and our methods.

\section{Summary}

1. A structurally constant and symmetrical lesion of the central white matter of the cerebrum has been produced in the rat by chronic $\mathrm{KCN}$ intoxication.

2. "Multiple acute softenings" have been experimentally produced, also in the rat, by micro- $\square$. embolization, by the intra-carotid injection of coagulants, and by chronic $\mathrm{CO}$ intoxication.

None of the lesions so produced resembles the $\underset{\Omega}{\mathbb{D}} \vec{T}$ cyanide lesion; nor do these techniques produce $\mathbb{Q}$ lesions in any way reminiscent of disseminated sclerosis in man.

3. The vascular and ferment hypotheses of $\vec{\varphi}$ spontaneous demyelinating disease are discussed,, and also the bearing upon these of the experimental cyanide lesion.

4. It is concluded that the degeneration of the white matter, once initiated by the cyanide, proceeds sui generis. The significance of this for the ferment hypothesis of spontaneous demyelinating disease is discussed.

I am indebted to Mr. N. Mowat, A.I.M.L.T., of the Department of Pathology of the University of Aberdeen, for the photography.

\section{REFERENCES}

Bielschowsky, M., and Henneberg, R. (1928). J. Psychol. Neurol., 36, 131.

Broman, T. (1940). Acta path. microbiol. scand., Suppl. XLII.

Dechaume, J., and Chambon, M. (1947). Arch. Mal. prof., 8, 119.

Eros, G., and Priestman, G. (1942). J. Neuropath. exper. Neurol., 1, 158.

Ferraro, A. (1933). Psychiat. Quart., 7, 267.

-1933). Arch. Neurol. Psychiat., Chicago, 29, 1364. Greenfield, J. G. (1938). J. Neurol.'Psychopath., 1, 306. - , and King, L. S. (1936). Brain, 59, 445. 
Gurdjian, E. S. (1927). J. comp. Neurol., 43, 1.

Hassin, G. B. (1937). Arch. Neurol. Psychiat., 38, 713.

Hurst, E. W. (1940). Aust. J. exp. Biol. med. Sci., 18, 201 .

_-(1942). Ibid., 20, 297.

Jedlowski, P. (1937) and (1938). Cited by Hurst, E. W.

Jervis, G. A., and Kindwall, J. (1942). Amer. J. Psychiat., 98, 650.

King, L. S., and Meehan, M. C. (1936). Arch. Neurol. Psychiat., 36, 547.
Lumsden, C. E. (1949). Brain, 72, 198.

Marburg, O. (1906). Jb. Psychiat., 27, 213.

Penfield, W. (1933). Ann. intern. Med., 7, 303.

Putnam, T. J., and Alexander, L. (1938). Assoc. Res. Nerv. Ment. Dis. Symposium, 18, 562, 563.

Spielmeyer, W. (1930). Z. Neurol. Psychiat., 123, 161. Verhaart, W. J. C. (1941). Amer. J. Dis. Child., 61, 1246.

Villaret, M., and Cachera, R. (1939). “Les Embolies Cérébrales." Paris. 